\title{
TEXTURE AND ELECTRICAL CONDUCTIVITY OF PELLETS PRESSED FROM PANI AND PANI/MONTMORILLONITE INTERCALATE
}

\author{
Jonáš TOKARSKÝ ${ }^{1) *}$, Kateřina MAMULOVÁ-KUTLÁKOVÁ ${ }^{1)}$, Lucie NEUWIRTHOVÁ ${ }^{1)}$, \\ Lenka KULHÁNKOVÁ ${ }^{2)}$, Vítězslav STÝSKALA ${ }^{3)}$, Vlastimil MATĚJKA ${ }^{1)}$ and Pavla ČAPKOVÁ ${ }^{4)}$
}

\author{
1) Nanotechnology Centre, VŠB - Technical University of Ostrava, 17. listopadu 15, 70833 Ostrava, Czech \\ Republic. Tel.: +420 597321 519, Fax.: +420597321640 \\ 2) Faculty of Metallurgy and Materials Engineering, V̌̌B - Technical University of Ostrava, 17. listopadu 15, \\ 70833 Ostrava, Czech Republic. Tel.: +420 597324 327, Fax.: +420 597321640 \\ 3) Faculty of Electrical Engineering and Computer Science, VЦ̆B - Technical University of Ostrava, \\ 17. listopadu 15, 70833 Ostrava, Czech Republic. Tel.: +420597321 511, Fax.: +420597321512 \\ 4) Faculty of Science, University of J. E. Purkyně, České mládeže 8, 40096 Usti nad Labem,Czech Republic. \\ Tel.: +420475283118, Fax.: +420475212053 \\ *Corresponding author's e-mail: jonas.tokarsky@vsb.cz
}

(Received March 2013, accepted September 2013)

\begin{abstract}
Polyaniline/montmorillonite (PANI/MMT) intercalate pressed into pellets using the pressure $28 \mathrm{MPa}$ has been prepared in order to achieve two-dimensional conductivity which is close to pure PANI, however with improved mechanical and thermal stability (due to the presence of silicate). Structure-conductivity relationship has been investigated using X-ray diffraction analysis and diffraction patterns obtained from two perpendicular planes revealed the strong texture. The structural anisotropy led to the anisotropy in conductivity, which is much stronger for PANI/MMT than for pure PANI pellets. Anyway, the inplane conductivity is of the same order for both PANI/MMT and pure PANI pellets. The anisotropy factor, that means the ratio of in-plane conductivity and conductivity in the direction perpendicular to the pellet plane, was 328 (PANI/MMT pellet) and 6.7 (pure PANI pellet), respectively.
\end{abstract}

KEYWORDS: clay; composite; conducting polymer; structure-property relations; synthesis and processing

\section{INTRODUCTION}

Hybrid nanocomposite materials based on conducting organic polymers are of interest in a wide range of applications in many fields, such as electrochromism, electroluminescence, sensors and energy storage systems (for review see for example (Lira-Cantú and Gómez-Romero, 2009)). In conducting polymer systems, chains alignment plays a key role (Cromack et al., 1991; Ou et al., 2003; Quadrat et al., 1998; Špírková et al., 1999; Costolo and Heeger, 2000; Wu et al., 2010; Adams et al., 1996; Cao et al., 1993; Shariki et al., 2011; Stejskal et al., 1997). Ordering of polymer chains can be achieved by various methods such as: mechanical orientation of polyaniline (PANI) films (Adams et al., 1996) using blends with insulating polymers (Cao et al., 1993; Shariki et al., 2011), ordering of PANI particles in monomer mixture in an electric field (Stejskal et al., 1997) or by using high pressure (Prokeš et al., 2011). Hybrid nanocomposites: PANI/phyllosilicate (Wu et al., 2000; Duran et al., 2009; Yoshimoto et al., 2004; Bekri-Abbes and Srasra, 2010) or PANI/ graphite (Wu et al., 2010) offer another way of PANI chains ordering due to the inclusion of platy particles of layered inorganic structures into polymeric matrix. In addition the interplay of PANI chains with inorganic materials can result in improved properties of nanocomposite, such as thermal and mechanical stability (Duran et al., 2009) or photovoltaic properties (Cuentas-Gallegos et al., 2005), etc. (for review see (Lira-Cantú and Gómez-Romero, 2009)).

Thanks to unique properties, clay minerals (phyllosilicates) have been widely employed as matrix for organo-inorganic composite materials (Lagaly et al., 2006; Ogawa and Kuroda, 1995; Lerf and Čapková, 2003). Layered structure of phyllosilicates offers a chance to intercalate the organic guest species including polymer chains into the interlayer space and to create high degree of structure ordering. In addition, the interaction of guest species with negatively charged layers of phyllosilicates can lead to new properties of these hybrid structures (Simha Martynková et al., 2007; Klika et al., 2007; Klika et al., 2009). Intercalation of conducting polymers into layered structure of phyllosilicates is expected to lead to nanocomposites with high degree of polymer ordering and with enhanced thermal and mechanical 
stability and gas barrier properties compared to pristine polymers (Alexander and Dubois, 2000).

Phyllosilicates, as well as all layered crystal structures, exhibit platy crystallites. Intercalation and surface modification preserves the plate-like shape of modified clay particles, which tend to preferred orientation of powder particles even by free filling of measuring cells without any pressure. Preparing pellets using pressure will lead to texture in nanocomposite structure, which is expected to dramatically affect electrical characteristics. Although the design of functional units based on these nanocomposites has to take into account this effect of texture, only few works focused on this topic can be found (Hutchison et al., 1996; Semakov et al., 2010). In the majority of articles dealing with PANI/phyllosilicate composites (and including measuring of pressed pellets conductivities) the anisotropy is not discussed. Applied pressure conductivity or PANI content - conductivity relationships are commonly presented but authors do not pay an attention to the conductivities of pellets in different directions (Prokeš et al., 2011; Wu et al., 2000; Kazim et al., 2012; Oyharcabal et al., 2012; Bober et al., 2010; Do Nascimento et al., 2006).

In the present work, montmorillonite (MMT) as a typical representative of smectite group of phyllosilicates has been chosen as a matrix for intercalation of conducting PANI. MMT exhibits relatively small layer charge and easy expansion of interlayer space and consequently easy intercalation of large guest molecules. Present work is focused on the texture - electrical conductivity relationship, using Xray diffraction analysis of texture together with directional conductivity measurements. Directional analysis of structure and conductivity was carried out for pressed pellets from pure PANI and PANI/MMT intercalate.

\section{MATERIALS AND METHODS}

\subsection{MATERIALS}

Na-MMT Portaclay ${ }^{\circledR}$ (The mineral company Ankerpoort NV, Netherland) with basal spacing 1.24 $\mathrm{nm}$ was used in this study. Aniline, sulfuric acid and ammonium peroxydisulfate were purchased from Lach-Ner, Czech Republic, and used as received.

\subsection{SAMPLE PREPARATION}

PANI powder was prepared using simple oxidative chemical polymerization of the solution of aniline in concentrated sulfuric acid by strong oxidizing agent at room temperature. The method is based on the mixing of two solutions: a) aniline solution in sulfuric acid $(0.5 \mathrm{M})$ which serves as cationic source, and b) solution of ammonium peroxodisulfate $(0.2 \mathrm{M})$ in distilled water which serves as an oxidizing agent. After the mixing of both solutions the polymerization of the aniline proceeds. This was signalized by the dark green colour of the reaction mixture. The time of the polymerization was 40 minutes. The green solids were collected on a filter by rinsing with distilled water and subsequently dried at $40{ }^{\circ} \mathrm{C}$ in a kiln.

PANI/MMT powder has been prepared using simple one-step process by the oxidative polymerization of anilinium sulfate with ammonium peroxydisulfate in aqueous suspension of MMT at room temperature. The MMT was suspended in freshly prepared aqueous reaction mixture containing aniline solution in sulfuric acid and $0.2 \mathrm{dm}^{3}$ solution of ammonium peroxydisulfate. The polymerization of aniline was completed within 40 minutes and the suspension was stirred still for 6 hours. The green solids were collected on a filter by rinsing with distilled water and subsequently dried at $40{ }^{\circ} \mathrm{C}$ in a kiln. Prepared PANI/MMT samples contained $\sim 56$ wt. $\%$ of PANI. During this one-step process the PANI chains were intercalated into the interlayer space of MMT structure. In the interlayer space of the pristine MMT, $\mathrm{Na}^{+}$cations have been exchanged for cationic PANI chains. This process led to the increase of the basal spacing from $1.24 \mathrm{~nm}$ to $1.31 \mathrm{~nm}$ (see further in section 3.1 Structure analysis and texture characterization).

Pressed pellets of pure PANI and PANI/MMT composite were prepared using LECO handpress (applied pressure $28 \mathrm{MPa}$ ) at room temperature, without any lubrication and without any binder. Portion of each powder sample before pressing was $3.0 \mathrm{~g}$. Pellets diameter was $32 \mathrm{~mm}$ but thicknesses of pellets were not the same - $2.7 \mathrm{~mm}$ for PANI/MMT and $4.2 \mathrm{~mm}$ for pure PANI - due to the different densities and compresibilities of PANI/MMT nanocomposite and pure PANI. The duration of pressing for each pellet was measured by stopwatch and recorded.

\subsection{X-RAY DIFFRACTION ANALYSIS}

The X-ray diffraction patterns were recorded using Bruker D8 Advance diffractometer (Bruker AXS, Germany) equipped with fast position sensitive detector VÅNTEC 1, with $\mathrm{CoK}_{\alpha}$ irradiation $(\lambda=$ $0.1789 \mathrm{~nm}$ ). All measurements were carried out in reflection mode in symmetrical Bragg-Brentano arrangement. In order to analyze the texture in pressed pellets, diffraction patterns have been recorded for two positions of pellets with respect to the diffraction plane (diffraction plane is defined by the incident and diffracted beam). For that purpose the pellets have been cut and the cutting plane has been carefully treated with brush before the diffraction measurements. X-ray diffraction patterns were recorded from pellet surface and cutting plane, respectively. Diffraction geometry is illustrated in Figure 1. In the first position, the pellet surface is perpendicular to the diffraction plane (i.e. normal to the surface of pellet lies in the diffraction plane; see Fig. 1a). In the second position the pellet surface is parallel to the diffraction plane and, therefore, the 

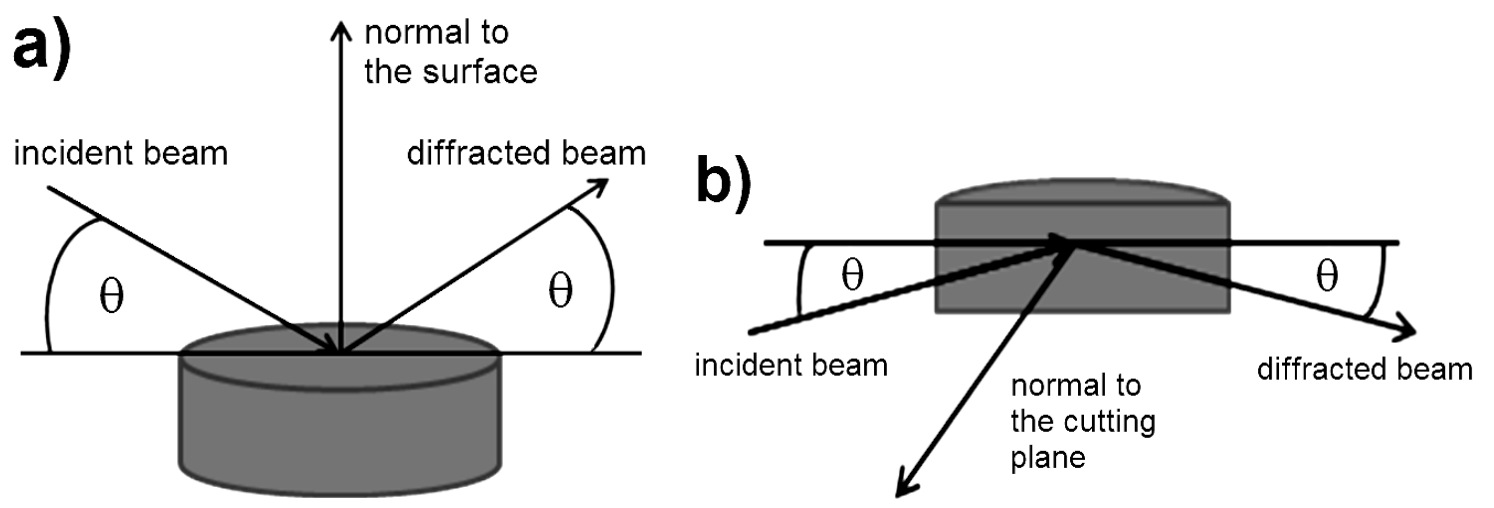

Fig. 1 Illustration of diffraction geometry for texture (preferred orientation) investigation in pellets.

cutting plane is perpendicular to the diffraction plane (i.e. normal to the cutting plane lies in the diffraction plane; see Fig. 1b).

\subsection{CONDUCTIVITY MEASUREMENTS}

Conductivity measurements have been carried out in three mutually perpendicular directions: (1) perpendicular to the pellet plane, i.e. in the direction of pressing (denoted as $\sigma_{\perp}$ ) and (2) in the pellet plane, i.e. perpendicularly to the direction of pressing (denoted as $\sigma_{\| I}$ and $\sigma_{\| 2}$ ). Last two values were averaged and the resulting value is denoted as $\sigma_{\| a v}$. For the schematic illustration of conductivity measurements see Figure 2. Two-point flat probe method has been used for DC conductivity measurements with contact $\mathrm{Cu}$ electrodes, where the special shape of curved surface of $\mathrm{Cu}$ electrodes has been designed for measurements in the direction perpendicular to the direction of pressing while the flat round $\mathrm{Cu}$ electrodes were used for the measurement in the direction of pressing. Measuring instruments: DC POWER SUPPLY HY 3003 D-2, Programmable DC POWER SUPPLY BK PRECISION 9120, multimeter AGILENT 34401A, V-meter UNI-T UT802, pA-meter KEITHLEY 6487.

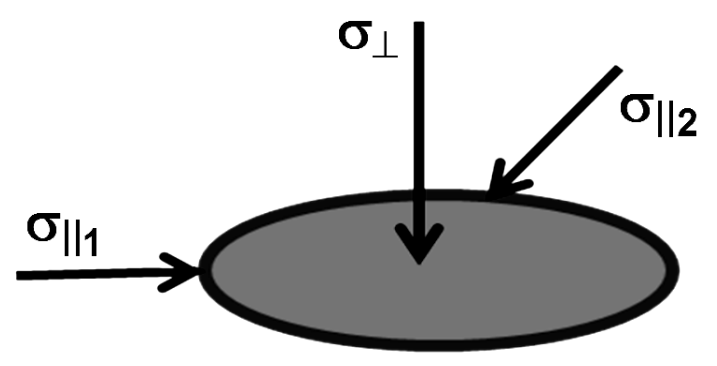

Fig. 2 Schematic illustration of conductivity measurements in three perpendicular directions.

\section{RESULTS AND DISCUSSION \\ 3.1. STRUCTURE ANALYSIS AND TEXTURE CHARACTERIZATION}

As one can see in Figure 3, the platy silicate particles in pellets are preferentially oriented with their 001 plane parallel to the flat pellet surface. Consequently, in the diffraction arrangement displayed in Figure 1a we can record preferentially the diffraction lines from $00 \mathrm{l}$ basal plane of MMT. Corresponding pattern is in Figure 3a. The asymmetric broaden peaks at $2 \theta \sim 23^{\circ}, 31^{\circ}$ and $41^{\circ}$ correspond to $h k$ - bands typical for smectites. The diffraction pattern from the cutting plane (in the arrangement displayed in Fig. 1b) is in Figure $3 b$. Comparing diffractions patterns in Figures $3 a$ and $3 b$, respectively, one can see in Figure $3 b$ the strong decrease of basal reflection with respect to $h k$ - bands in case of diffraction on cutting plane, which means the presence of strong texture in the pellets.

Analysis of X-ray diffraction patterns (see Figs. $3 \mathrm{a}$ and $3 \mathrm{~b}$ ) revealed following important structural features of PANI/MMT pellets.

1. Strong preferred orientation in the sample texture type 001. Typical attributes of this texture are: strong intensity for 001 reflection at $2 \theta=6.5$ in comparing with the intensity of $h k$ - band characterizing the periodicity in silicate layer planes at $2 \theta \sim 23^{\circ}$ for diffraction arrangement in Figure 1a. On the other hand by diffraction arrangement displayed in Figure $1 \mathrm{~b}$ we can observe dramatic change of $001 / h k$ band intensity ratio (compare Fig. 3b with Fig. 3a).

2. First basal reflection 001 at $2 \theta \sim 6.5^{\circ}$ corresponds to the basal spacing $1.31 \mathrm{~nm}$, what indicates the change of interlayer structure of pristine MMT after one step composite preparation. The relatively sharp 001 profile in comparison with other PANI/clay intercalates (see for example (Kulhánková et al., 2012)) indicates that MMT was fully intercalated by PANI chains. Intercalation of PANI has significant effect on the in-plane conductivity of pellets, as will be discussed further. 

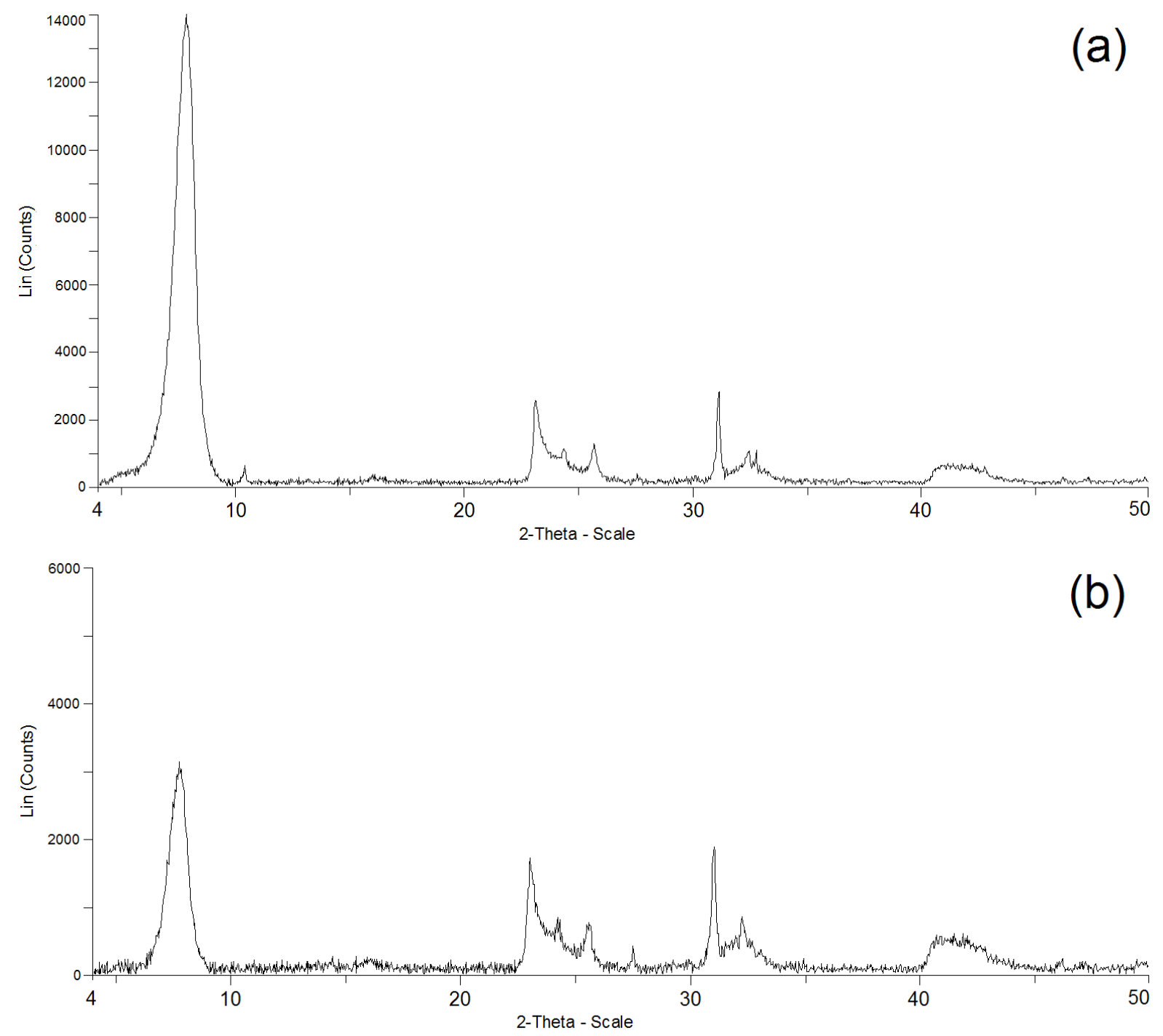

Fig. 3 (a) Diffraction pattern of pressed pellets from PANI/MMT intercalate recorded from diffraction plane perpendicular to the pellet plane (see arrangement in Figure 1a); and

(b) diffraction pattern recorded from cutting plane (see arrangement in Figure 1b).

3. In the $2 \theta$ range of $14-18^{\circ}$ we can observe also an inkling of very small broaden peak of pure PANI component occurring between silicate plates.

Diffractograms of the pellet surface plane and the cutting plane for the pure PANI pellet is in Figures $4 a$ and $4 b$, respectively. The difference in both diffractograms is evident and indicates the strong texture in pure PANI pellets. That means the morphology of pure PANI particles is also strongly anisotropic. The flakes, ribbons and nanorods have been reported in (Laslau et al., 2012), where the PANI chains are parallel with rods and ribbons axis or with the flake planes. Consequently in the diffractogram of pellet plane we can record preferentially the reflections from planes parallel to chains, and consequently the peaks at $0.60,0.44$ and $0.35 \mathrm{~nm}$ correspond to periodicity in stacking and ordering of PANI chains in planes parallel to flake planes or in planes forming a low angle with the flake planes. On the other hand, the diffractogram of the cutting plane (see Fig. 4b) exhibits one strong peak at $0.74 \mathrm{~nm}$ corresponding to the periodicity in planes perpendicular to flake plane/ribbon plane. Peaks corresponding to tilted planes at 0.60 and $0.35 \mathrm{~nm}$ are observable on both patterns. Laslau et al. (2012) investigated the structure of PANI powder samples in capillary using synchrotron diffraction. In spite of different experimental conditions - capillary (Laslau et al., 2012) versus the flat textured sample (our work) there is quite good agreement in peaks at $\sim 0.35,0.44$ and $0.60 \mathrm{~nm}$.

\subsection{CONDUCTIVITY MEASUREMENT}

Results of DC conductivity measurements are summarized in the Table 1 , where $\sigma \perp$ is the conductivity in direction perpendicular to the pellet 

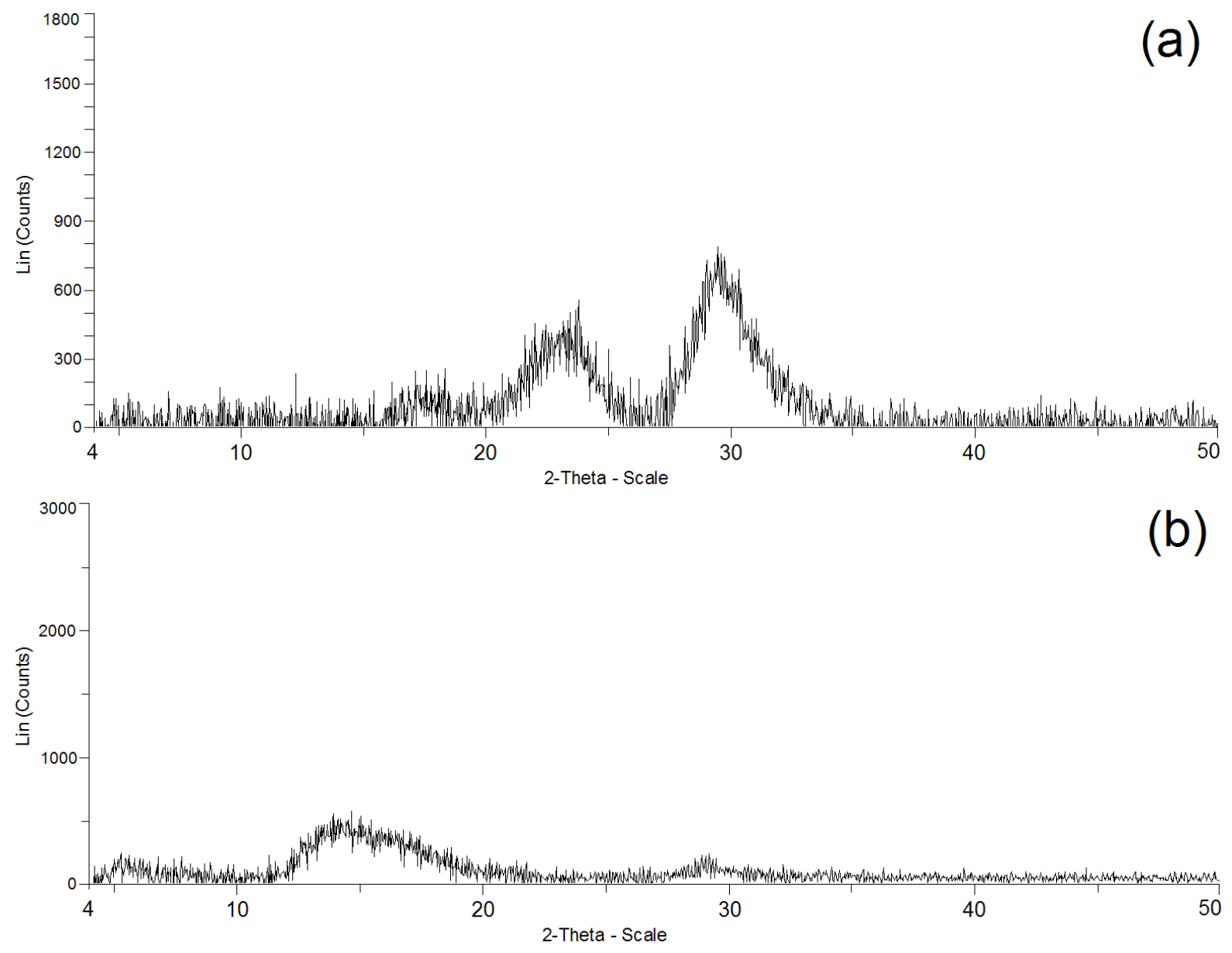

Fig. 4 (a) Diffraction pattern of pressed pellets from pure PANI recorded for diffraction plane perpendicular to the pellet plane (see arrangement in Figure 1a); and

(b) diffraction pattern recorded from cutting plane (see arrangement in Figure 1b).

Table 1 DC conductivities in three perpendicular directions for two pellets pressed from PANI/MMT powder in two different pressing times (see the time in parentheses) and one pellet pressed from pure PANI powder. The values of anisotropy factor (expressed as $\sigma_{\| a v} / \sigma_{\perp}$ ratio) are listed in the bottom row.

\begin{tabular}{|c|c|c|c|}
\hline \multirow[t]{2}{*}{ directions } & \multicolumn{3}{|c|}{ conductivity $1 \cdot 10^{-3}\left[\mathrm{~S} \cdot \mathrm{cm}^{-1}\right]$} \\
\hline & $\begin{array}{l}\text { PANI/MMT } \\
\text { (20 min) }\end{array}$ & $\begin{array}{l}\text { PANI/MMT } \\
\text { (17 min) }\end{array}$ & $\begin{array}{c}\text { PANI } \\
(22 \mathrm{~min})\end{array}$ \\
\hline$\sigma_{\perp}$ & 0.0149 & 0.0380 & 1.0370 \\
\hline$\sigma_{\| 1}$ & 4.8904 & 4.6179 & 7.3118 \\
\hline$\sigma_{\| 2}$ & 4.8904 & 4.6341 & 6.5591 \\
\hline$\sigma_{\| a v}$ & 4.8904 & 4.6260 & 6.9355 \\
\hline \multicolumn{4}{|c|}{ anisotropy factor [-] } \\
\hline$\alpha=\sigma_{\| a v} / \sigma_{\perp}$ & 328.2 & 121.7 & 6.7 \\
\hline
\end{tabular}

plane, $\sigma_{|| 1}$ and $\sigma_{|| 2}$, respectively, are the conductivity values in the pellet plane in two perpendicular directions (for an arrangement see Fig. 2) and $\sigma_{\| a v}$ is an average of $\sigma_{\| 1}$ and $\sigma_{\| 2}$ values. Value $\alpha$ is the anisotropy factor, a dimensionless $\sigma_{\| a v} / \sigma_{\perp}$ ratio.

Values in first two columns of Table 1 correspond to PANI/MMT intercalate exposed to the pressure $28 \mathrm{MPa}$ for $20 \mathrm{~min}$ (in the first column) and for $17 \mathrm{~min}$ (in the second column). Conductivity values of pure PANI pellet pressed at $28 \mathrm{MPa}$ for $22 \mathrm{~min}$ is in the third column for comparison. One can see that for pressing pellets from PANI/MMT powder the shorter time was needed than for pressing pellets from pure PANI. This is caused by better structural 
ordering of PANI chains in PANI/MMT powder than in pure PANI powder.

Results of conductivity measurements can be summarized as follows.

1. It is evident, that the strong texture revealed for all samples by diffraction measurements manifests itself by the strong anisotropy in conductivity.

2. The longer pressing time allows better arrangement of MMT layers in the direction perpendicular to the direction of pressing. This fact leads to a lower $\sigma_{\perp}$ conductivity and consequently to the stronger anisotropy, as one can see comparing first and second columns in the Table 1.

3. While for the PANI/MMT composite the strong texture and anisotropy was expected, because of the morphology of clay particles, the pure PANI pellets exhibit quite remarkable anisotropy as well.

4. While in the direction perpendicular to the pellet plane the conductivity $\sigma_{\perp}$ is about 100 times lower for PANI/MMT composite than for pure PANI, the $\sigma_{\| a v}$ values for composite and pure PANI are of the same order $\left(1 \cdot 10^{-3}\right)$. This agreement in inplane conductivity for PANI/MMT and pure PANI is the consequence of the fully intercalated structure of MMT, confirmed by X-ray diffraction.

5. Present values of conductivity for pure PANI $\sigma_{\perp}$ and $\sigma_{\| a v}$ are lower than values published by (Stejskal et al., 2002 and Prokeš et al., 2011) $\sim 5.1 \mathrm{~S} \cdot \mathrm{cm}^{-1}$. On the other hand, (Kazim et al., 2012) reported preparation of pellets pressed from PANI/MMT composite under the pressure $\sim 490 \mathrm{MPa}$ and found the conductivity an order of magnitude lower $\left(1.6-7.410^{-4} \mathrm{~S} \cdot \mathrm{cm}^{-1}\right)$. However, the comparison is difficult as the previously published results have been obtained using pellets pressed at much higher pressure $(700 \mathrm{MPa}$ in (Prokeš et al., 2011 and Stejskal et al., 2002), 490 $\mathrm{MPa}$ in (Kazim et al., 2012)). In addition, (Stejskal et al., 2002 and Prokeš et al., 2011) carried out the measurement using van der Pauw four-point method which represents different experimental configuration than in our work.

\section{CONCLUSIONS}

Present study showed the relationship between structure and conductivity of pressed pellets of PANI/MMT and PANI analyzing the texture in samples. The main result of this work is the conclusion, that the in-plane conductivity $\sigma_{\| a v}$ of PANI/MMT composite and pure PANI pellets is nearly the same. This is promising result as to future practical applications, as it means that we can get a functional unit of PANI/MMT composite with the two-dimensional conductivity, which is the same as for pure PANI. The main advantage of PANI/MMT composite is the high anisotropy factor $\alpha=\sigma_{\| a v} / \sigma_{\perp}$ (328.2 for PANI/MMT and 6.7 for pure PANI), which means the better chance for design of two-dimensional conductor. In addition, this PANI/MMT functional unit will be more mechanically and thermally stable than pure PANI, thanks to the presence of silicate layers.

\section{ACKNOWLEDGEMENT}

This research has been funded by the Grant Agency of Czech Republic (project P108/11/1057). This paper has been elaborated in the framework of the Nanotechnology - the basis for international cooperation project, reg. no. CZ.1.07/2.3.00/20.0074 supported by Operational Programme 'Education for competitiveness' funded by Structural Funds of the European Union and state budget of the Czech Republic.

\section{REFERENCES}

Adams, P.N., Laughlin, P.J. and Monkman, A.P.: 1996, Synthesis of high molecular weight polyaniline at low temperatures, Synth. Met., No. 76 (1-3), 157-160. DOI: 10.1016/0379-6779(95)03442-M

Alexander, M. and Dubois, P.: 2000, Polymer-layered silicate nanocomposites: preparation, properties and uses of a new class of materials, Mater. Sci. Eng. A, No. 28, 1-63. DOI: 10.1016/S0927-796X(00)00012-7

Bekri-Abbes, I. and Srasra, E.: 2010, Solid-state synthesis and electrical properties of polyaniline/Cu-montmorillonite nanocomposite, Mater. Res. Bull., No. 45 (12), 1941-1947.

DOI: 10.1016/j.materresbull.2010.08.012

Bober, P., Stejskal, J., Špírková, M., Trchová, M., Varga, M. and Prokeš, J.: 2010, Conducting polyanilinemontmorillonite composites, Synth. Met., 160 (23-24), 2596-2604. DOI: 10.1016/j.synthmet.2010.10.010

Cao, Y., Smith, P. and Heeger, A.J.: 1993, Counter-ion induced processibility of conducting polyaniline, Synth. Met., No. 57 (1), 3514-3519. DOI: 10.1016/0379-6779(93)90468-C

Costolo, M. and Heeger, A.J.: 2000, Anisotropic conductivity in polyaniline and image processing applications, Synth. Met., No. 114 (1), 85-90. DOI: 10.1016/S0379-6779(00)00235-6

Cromack, K.R., Jozefowicz, M.E., Ginder, J.M., Epstein, A.J., McCall, R.P., Du, G., Leng, J.M., Kim, K., Wang, Z.H., Druy, M.A., Glatkowski, P.J., Seherr, E.M. and MacDiarmid, A.G.: 1991, Thermal process for orientation of polyaniline films, Macromolecules, No. 24, 4157-4161. DOI: 10.1021/ma00014a031

Cuentas-Gallegos, K., Lira-Cantú, M., Casaň-Pastor, P. and Gómez-Romero, P.: 2005, Nanocomposite Hybrid molecular materials for application in solid-state electrochemical supercapacitors, Adv. Funct. Mater., No. 15 (7), 1125-1133. DOI: 10.1002 adfm.200400326

Do Nascimento, G.M., Constantino, V.R.L., Landers, R. and Temperini, M.L.A.: 2006, Spectroscopic characterization of polyaniline formed in the presence of montmorillonite clay, Polymer, No.47 (17), 61316139. DOI: 10.1016/j.polymer.2006.06.036 
Duran, N.G., Karakısla, M., Aksu, L. and Sacak, M.: 2009, Conducting polyaniline/kaolinite composite: synthesis, characterization and temperature sensing properties, Mater. Chem. Phys., No. 118, 93-98. DOI: 10.1016/j.matchemphys.2009.07.009

Hutchison, J.C., Bissessur, R. and Shiver, D.F.: 1996, Conductivity anisotropy of polyphosphazenemontmorillonite composite electrolytes, Chem. Mater., No. 8, 1597-1599. DOI: 10.1021/cm960039w

Kazim, S., Shahzada, A., Pfleger, J., Plestil, J. and Joshi, Y.M.J.: 2012, Polyaniline-sodium montmorillonite clay nanocomposites: effect of clay concentration on thermal, structural, and electrical properties, Mater. Sci., No. 47 (1), 420-428.

DOI: $10.1007 / \mathrm{s} 10853-011-5815-\mathrm{y}$

Klika, Z., Čapková, P., Horáková, P., Valášková, M., Malý, P., Macháň, R. and Pospíšil, M.: 2007, Composition, structure, and luminescence of montmorillonites saturated with different aggregates of methylene blue, J. Colloid Interface Sci., No. 311, 14-23.

DOI: $10.1016 /$ j.jcis.2007.02.034

Klika, Z., Pustková, P., Praus, P., Kovář, P., Pospíšil, M., Malý, P., Grygar, T., Kulhánková, L. and Čapková, P.: 2009, Fluorescence of reduced charge montmorillonite complexes with methylene blue: Experiments and molecular modeling, J. Colloid Interface Sci., No. 339, 416-423. DOI: 10.1016/j.jcis.2009.07.062

Kulhánková, L., Tokarský, J., Peikertová, P., Mamulová Kutláková, K., Ivánek, L. and Čapková, P.: 2012, Montmorillonite intercalated by conducting polyanilines, J. Phys. Chem. Solids, No.73, 15301533. DOI: 10.1016/j.jpcs.2011.11.043

Lagaly, G., Ogawa, M. and Dékány, I.: 2006, Handbook of clay science, developments in clay science: Bergaya, F., Theng, B.K.G., Lagaly, G. (Eds.): Elsevier, Amsterdam, Vol. 1, Chapter 7.3, 309-377.

Laslau, C., Ingham, B., Zujovic, Z. D., Čapková, P., Stejskal, J., Trchová, M. and Travas-Sejdic, J.: 2012, Synth. Met., 161 (23-24), 2739-2742. DOI: 10.1016/j.synthmet.2011.10.012

Lerf, A. and Čapková, P.: 2003, Encyclopedia of nanoscience and nanotechnology: Nalva, H.S. (Ed).: American Scientific publishers, Stevenson Ranch, CA, USA, Vol. X, Chapter 1, 1-54.

Lira-Cantú, M. and Gómez-Romero, P.: 2009, Hybrid nanocomposites for nanotechnology: electronic, optical, magnetic and biomedical applications. Merhari, L. (Ed.): Springer Science + Bussiness Media, LLC: New York, 288 pp.

Ogawa, M. and Kuroda, K.: 1995, Photofunctions of intercalation compounds, Chem. Rev., No. 95 (2), 399--438. DOI: 10.1021/cr00034a005

$\mathrm{Ou}$, R., Gerhardt, R.A. and Samuels, R.J.: 2003, Structureelectrical property study of anisotropic polyaniline films, J. Polym. Sci. B, No. 41 (8), 823-841. DOI: $10.1002 /$ polb. 10430

Oyharcabal, M., Oling, T., Foulc, M.P. and Vigneras, V.: 2012, Polyaniline/clay as nanostructured conductive filler for electrically conductive epoxy composites. Influence of filler morphology, chemical nature of reagents, and curing conditions on composite conductivity, Synth. Met., No. 162 (7-8), 555-562.

DOI: 10.1016/j.synthmet.2012.02.011
Prokeš, J., Varga, M., Křivka, I., Rudajevová, A. and Stejskal, J.: 2011, The influence of compression pressure on transport properties of polyaniline, J. Mater. Chem., No. 21, 5038-5045. DOI: $10.1039 / \mathrm{c} 0 \mathrm{jm} 03087 \mathrm{~b}$

Quadrat, O., Stejskal, J., Kratochvíl, P., Klasson, C., McQueen, D., Kubát, J., Sáha, P.: 1998, Electrical properties of polyaniline suspensions, Synth. Met., No. 97 (1), 37-42. DOI: 10.1016/S0379-6779(98)00107-6

Semakov, A.V., Shabeko, A.A., Kiseleva, S.G., Orlov, A.V., Rebrov, A.V., Korolev, Y.M., Karpacheva, G.P., Kuleznev, V.N. and Kulichikhin, V.G.: 2010, Anisotropic electroconducting polymer-silicate composites based on polyaniline, Polym. Sci. B, No. 52 (1-2), 91-100. DOI: 10.1134/S156009041001015X

Shariki, S., Liew, S.Y., Thielemans, W., Walsh, D.A., Cummings, C.Y., Rassaei, L., Wasbrough. M.J., Edler, K.J., Bonne, M.J. and Marken, F.J.: 2011, Tuning percolation speed in layer-by-layer assembled polyaniline-nanocellulose composite films, Solid State Electrochem., No. 15 (11-12), 2675-2681. DOI: $10.1007 / \mathrm{s} 10008-010-1261-\mathrm{z}$

Simha Martynková, G., Kulhánková, L., Malý, P. and Čapková, P.: 2007, Fluorescence and structure of methyl red-clay nanocomposites, J. Nanosci. Nanotechnol., No. 8 (1-6), 2069-2074. DOI: 10.1166/jnn.2008.058

Stejskal, J., Špírková, M., Quadrat, O. and Kratochvíl, P.: 1997, Electrically anisotropic materials: polyaniline particles organized in a polyurethane network, Polym. Int., No. 44, 283-287. DOI: 10.1002/(SICI)10970126(199711)44:3<283::AID-PI878>3.0.CO;2-9

Stejskal. J. and Gilbert, R.G.: 2002, Polyaniline. preparation of a conducting polymer, Pure Appl. Chem., No. 74 (5), 857-867. DOI: 10.1351/pac200274050857

Špírková, M., Stejskal, J. and Quadrat, Q.: 1999, Electrically anisotropic polyaniline-polyurethane composites, Synth. Met., No. 102 (1-3), 1264-1265. DOI: 10.1016/S0379-6779(98)01461-1

Wu, X., Qi, S., He, J. and Duan, G.J.: 2010, High conductivity and low percolation threshold in polyaniline/graphite nanosheets composites, Mater. Sci., No. 45 (2), 483-489. DOI: $10.1007 / \mathrm{s} 10853-009-3965-\mathrm{y}$

Wu, Q., Xue, Z., Qi, Z. and Wang, F.: 2000, Synthesis and characterization of PAn/clay nanocomposite with extended chain conformation of polyaniline, Polymer, No. 41, 2029-2032. DOI: 10.1016/S0032-3861(99)00356-0

Yoshimoto, S., Ohashi, F., Ohnishi, Y. and Nonami, T.: 2004, Synthesis of polyaniline-montmorillonite nanocomposites by the mechanochemical intercalation method, Synth. Met., No. 145 (2-3), 265-270. DOI: $10.1016 /$ j.synthmet.2004.05.011 